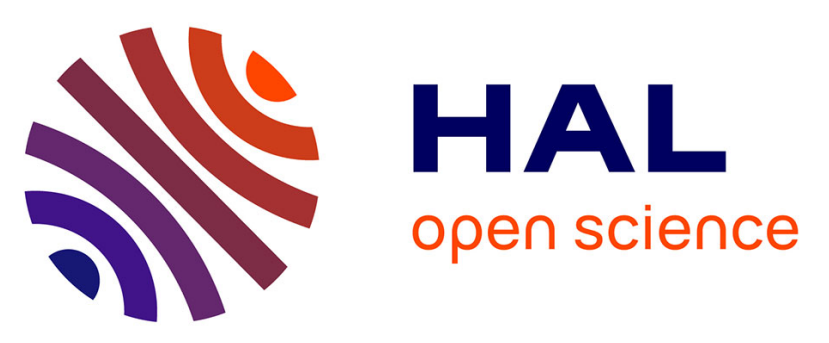

\title{
Double Catalytic Kinetic Resolution (DoCKR) of Acyclic anti-1,3-Diols: The Additive Horeau Amplification
}

Jérémy Merad, Prashant Borkar, Frédéric Caijo, Jean-Marc Pons, Jean-Luc Parrain, Olivier Chuzel, Cyril Bressy

\section{To cite this version:}

Jérémy Merad, Prashant Borkar, Frédéric Caijo, Jean-Marc Pons, Jean-Luc Parrain, et al.. Double Catalytic Kinetic Resolution (DoCKR) of Acyclic anti-1,3-Diols: The Additive Horeau Amplification. Angewandte Chemie International Edition, 2017, 56, pp.16052-16056. 10.1002/anie.201709844 . hal01687281

\section{HAL Id: hal-01687281 https://hal.science/hal-01687281}

Submitted on 18 Jan 2018

HAL is a multi-disciplinary open access archive for the deposit and dissemination of scientific research documents, whether they are published or not. The documents may come from teaching and research institutions in France or abroad, or from public or private research centers.
L'archive ouverte pluridisciplinaire HAL, est destinée au dépôt et à la diffusion de documents scientifiques de niveau recherche, publiés ou non, émanant des établissements d'enseignement et de recherche français ou étrangers, des laboratoires publics ou privés. 


\title{
Double Catalytic Kinetic Resolution (DoCKR) of Acyclic anti-1,3- Diols: The Additive Horeau Amplification
}

\author{
Jérémy Merad, Prashant Borkar, Frédéric Caijo, Jean-Marc Pons, Jean-Luc Parrain, \\ Olivier Chuzel,* and Cyril Bressy*
}

\begin{abstract}
The concept of a synergistic double catalytic kinetic resolution (DoCKR) as described in this article was successfully applied to racemic acyclic anti-1,3-diols, a common motif in natural products. This process takes advantage of an additive Horeau amplification involving two successive enantioselective organocatalytic acylation reactions, and leads to diesters and recovered diols with high enantiopurities. It was first developed with $C_{2}$-symmetrical diols and then further extended to non- $C_{2}-$ symmetrical anti diols to prepare useful chiral building blocks. The protocol is highly practical as it only requires $1 \mathrm{~mol} \%$ of a commercially available organocatalyst and leads to easily separable products. This procedure was applied to the shortest reported total synthesis of (+)-cryptocaryalactone, a natural product with anti-germinative activity.
\end{abstract}

$H_{\text {ow can one improve the enantioselectivity outcome of }}$ a reaction on a wide scope? This question arises during the development of any given catalytic enantioselective transformation. The indispensable optimization stage improves the enantiomeric ratio (e.r.) of a reaction through the variations of the chemical and/or physical parameters of the transformation. Usually, e.r. enhancement is rapidly accompanied by a narrowing of the reaction scope. Most of the time, the rational design of the catalyst structure is the only option to improve reactivity and selectivity. This fine-tuning is nonetheless time consuming because of the difficulty of considering all the parameters involved in the enantiodetermining transition state, even though it can result in negligible improvements.

In contrast, the Horeau principle ${ }^{[1]}$ is responsible for the improvement of enantioselectivity in some reactions which rely on polyfunctionalized substrates. By applying at least two identical successive enantioselective transformations, the second reaction can act as an additional stereocontrolling filter to improve the enantiopurity of the final product. Since the pioneering works of Horeau in the $70^{\prime}$ s, such amplification of enantioselectivity was observed in several catalytic trans-

[*] Dr. J. Merad, Dr. P. Borkar, Prof. Dr. J.-M. Pons, Dr. J.-L. Parrain, Dr. O. Chuzel, Prof. Dr. C. Bressy

Aix Marseille Université, CNRS, Centrale Marseille, iSm2 Marseille (France)

E-mail: olivier.chuzel@univ-amu.fr cyril.bressy@univ-amu.fr

Dr. F. Caijo

DemetaSAS

6 rue Pierre Joseph Colin, Biopole, 35500 Rennes (France) formations. ${ }^{[2,3,5 e]}$ In enantioselective catalysis, the Horeau amplification can be divided into two main categories:

1) In the subtractive Horeau amplification, the minor enantiomer obtained after the first transformation is the substrate of the second transformation. The polyfunctionalized substrates involved in this first category are either prochiral ${ }^{[3,4]}$ or meso compounds. ${ }^{[3,5]}$

2) In the additive Horeau amplification, the major enantiomer formed after the first reaction is rapidly consumed in the second enantioselective (or diastereoselective) transformation. ${ }^{[6]}$ However, in contrast to the subtractive processes, examples of additive amplifications involving starting materials with pre-existing stereocenters are extremely scarce (Scheme 1). ${ }^{[7]}$

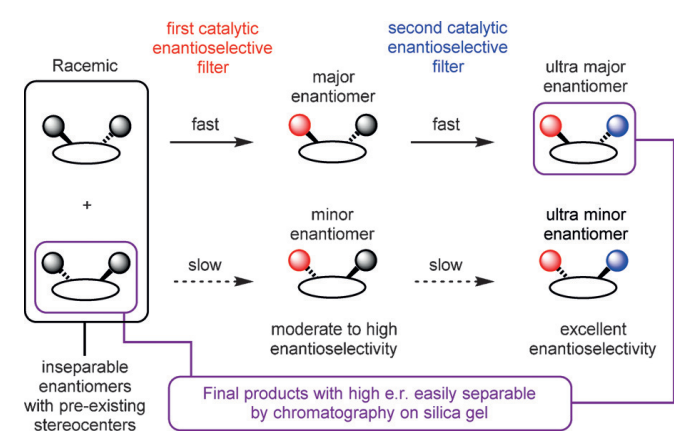

Scheme 1. Additive Horeau amplification applied to substrates bearing pre-existing stereocenters.

Although observed many times, the Horeau amplification is still considered an anecdotal phenomenon. By considering the synthetic potential supported by the Horeau principle in enantioselective catalysis, we supposed that this concept could be used as a synthetic strategy. Indeed, it could constitute an alternative approach to laborious catalyst finetuning while keeping high enantioselectivities and broad reaction scopes. In practice, the syntheses designed on this principle would require minimal optimization and remain effective with moderately selective catalysts. To validate this hypothesis we identified the double catalytic kinetic resolution (DoCKR) of acyclic anti-1,3-diols as a relevant transformation, complementary to our previous study. ${ }^{[\mathrm{dd}]}$ Indeed, this widespread stereodefined scaffold is, to a large extent, responsible for the biological activity of numerous polyketides such as dictyostatin, ripostatin B, fostriecin, and peluroside $\mathrm{A}^{\left[{ }^{[8]}\right.}$ Consequently, the control of relative and 
absolute configurations is particularly pivotal. ${ }^{[9]}$ Generally, these motifs are obtained thanks to the preparation of an enantioenriched $\beta$-hydroxyketone followed by its anti-diastereoselective reduction ${ }^{[10]}$ (Scheme $2 \mathrm{a}$ ). However, few meth-

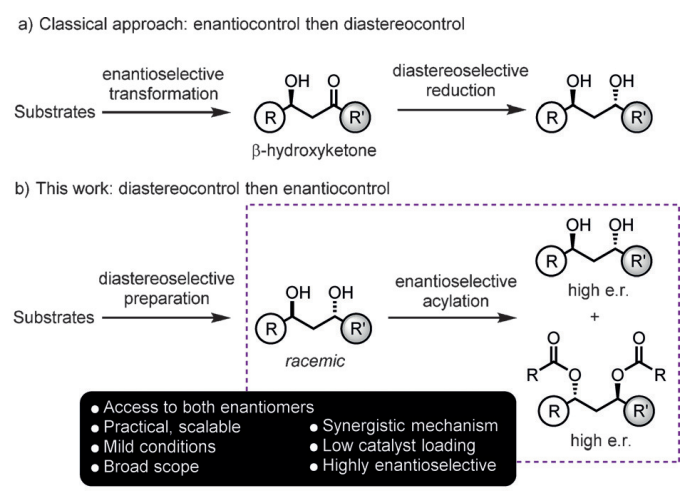

c) Mechanistic scenario of DoCKR of anti-1,3-diols: Additive Horeau amplification

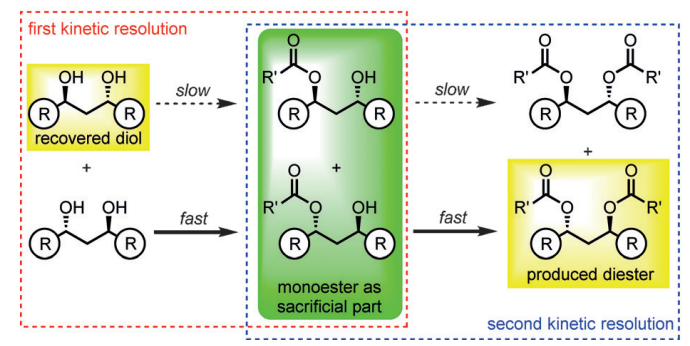

Scheme 2. a) Classical approach to prepare enantioenriched acyclic anti-1,3-diols. b) DoCKR for acyclic racemic anti-1,3-diols. c) Mechanistic scenario of the DoCKR.

ods are catalytic and enantioselective. ${ }^{[6, g, g 11]}$ In contrast, an approach in which the diastereoselectivity is set first and then the enantiocontrol is secured, could offer new opportunities. We envisioned that this second step could be provided by an enantioselective acylation of the corresponding anti diols (Scheme 2b). However, such organocatalytic KR of acyclic anti-1,3-diols ${ }^{[12]}$ remains unprecedented because it faces massive challenges: 1) the high flexibility of the substrates and the lack of catalysts able to induce an efficient stereocontrol; 2) the potential formation of multiple side products and undesired isomers.

We assumed that such a challenging transformation could be achieved through an additive Horeau amplification. It could result from a DoCKR process in which an enantioselective esterification would be followed by a second acyl transfer to the major enantiomer (Scheme $2 \mathrm{c}$ ). The produced diester and the recovered diol of opposite absolute configurations should both be obtained with a high level of enantioselectivity. The monoester fraction would constitute the sacrificial part of the amplifying process.

We started our study with the $C_{2}$-symmetrical substrate $\mathbf{1 a}$ (Scheme 3), synthesized in only two steps (d.r. $>20: 1$ ). This compound displays two easy post-transformable $\mathrm{C}-\mathrm{C}$ double

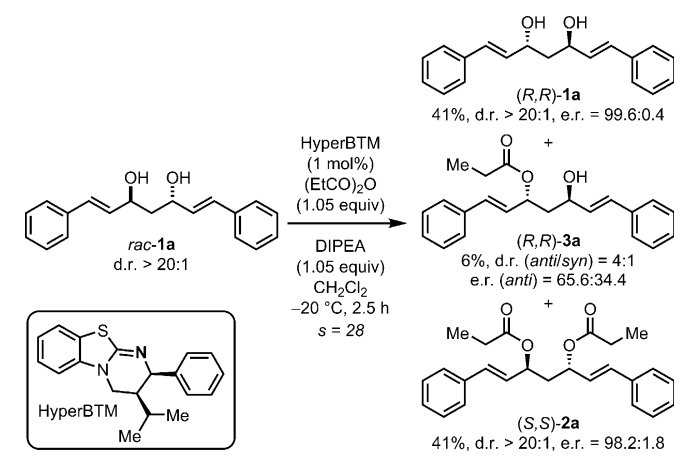

Scheme 3. Validation of the hypothesis and optimized reaction conditions for the DoCKR. DIPEA=diisopropylethylamine.

bonds, thus providing rigidity and possible interactions with the catalyst. Based on our previous work, and deliberately avoiding any catalyst screening, we selected the commercially available HyperBTM ${ }^{[13]}$ as a promising chiral catalyst. A brief optimization of the reaction conditions (see the Supporting Information) led us to identify a combination of propionic anhydride with $1 \mathrm{~mol} \%$ of HyperBTM as extremely efficient in terms of yield and selectivity. Indeed, under these standard reaction conditions, $(R, R)-\mathbf{1 a}$ was recovered in $41 \%$ yield (out of a maximum of 50\%) and 99.6:0.4 e.r. while the diester $(S, S)$-2a was produced in $41 \%$ yield (out of a maximum of $50 \%)$ and 98.0:2.0 e.r. As expected, the small monoester fraction $(R, R)-\mathbf{3 a}(6 \%)$ was obtained with a poor selectivity serving in the process as the sacrificial part. Interestingly, the small initial amount of syn diol contaminating the racemic anti diol was also captured as its monoester. It is noteworthy that each fraction is easily separable by simple chromatography thus making this process facile.

To confirm the beneficial effect of the double enantioselective acylation, the KR of racemic $\mathbf{3} \mathbf{a}$ was conducted under similar reaction conditions but with reduced amounts of anhydride and base (Scheme 4). As expected, the single enantioselective acyl transfer resulted in lower levels of selectivity and an $s$ value ${ }^{[14]}$ of 17 . This value was increased to 28 when the DoCKR process was performed on $\mathbf{1 a}$ (Table 1, entry 1). The additive Horeau amplification transforms a reaction displaying a moderate intrinsic selectivity into a highly enantioselective synthetic methodology.

The scope of the DoCKR was then examined with racemic $C_{2}$-symmetrical 1,3-diols bearing $\pi$-systems in either

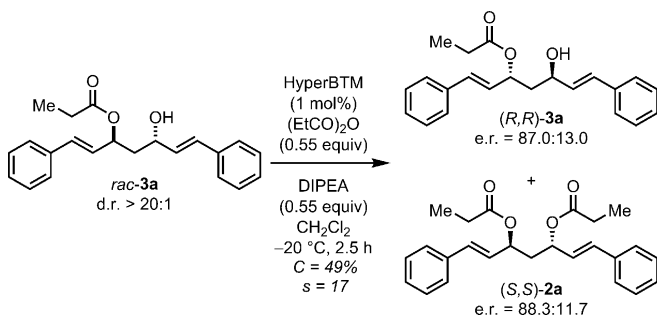

Scheme 4. KR of the racemic monoester $3 \mathrm{a}$. 


\begin{tabular}{|c|c|c|c|c|}
\hline \multirow[t]{2}{*}{ Entry } & \multirow[t]{2}{*}{$r a c-1$} & \multicolumn{3}{|c|}{ Yield $[\%]^{[b]}(\text { e.r. })^{[c]}$} \\
\hline & & $\operatorname{Diol}^{[\mathrm{e}]}$ & Diester ${ }^{[e]}$ & \\
\hline 1 & & $\begin{array}{l}40^{[f]} \\
(98.4: 1.6)\end{array}$ & $\begin{array}{l}47^{[f]} \\
(99.3: 0.7)\end{array}$ & \\
\hline 2 & & $\begin{array}{l}40 \\
(97.6: 2.4)\end{array}$ & $\begin{array}{l}40 \\
(98.9: 1.1)\end{array}$ & 16 \\
\hline 3 & & $\begin{array}{l}43 \\
(>99.9: 0.1)\end{array}$ & $\begin{array}{l}44 \\
(99.6: 0.4)\end{array}$ & 51 \\
\hline 4 & & $\begin{array}{l}40 \\
(97.1: 2.9)\end{array}$ & $\begin{array}{l}44 \\
(98.3: 1.7)\end{array}$ & 15 \\
\hline 5 & & $\begin{array}{l}46 \\
(98.7: 1.3)\end{array}$ & $\begin{array}{l}46 \\
(98.1: 1.9)\end{array}$ & \\
\hline 6 & & $\begin{array}{l}44 \\
(>99.9: 0.1)\end{array}$ & $\begin{array}{l}40 \\
(99.9: 0.1)\end{array}$ & 60 \\
\hline 7 & & $\begin{array}{l}43 \\
(>99.9: 0.1)\end{array}$ & $\begin{array}{l}42 \\
(97.4: 2.6)\end{array}$ & 51 \\
\hline 8 & & $\begin{array}{l}45 \\
(>99.9: 0.1)\end{array}$ & $\begin{array}{l}45 \\
(98.6: 1.4)\end{array}$ & 73 \\
\hline$g^{[\mathrm{g}]}$ & & $\begin{array}{l}21 \\
(99.5: 0.5)\end{array}$ & $\begin{array}{l}19 \\
(61.2: 38.8)\end{array}$ & 7 \\
\hline
\end{tabular}

[a] Typical experiment performed on $0.5 \mathrm{mmol}$ of the racemic diol under the standard reaction conditions. [b] Yield of isolated product.

[c] Determined by HPLC analysis using a stationary chiral phase; for details see the Supporting Information. [d] Based on recovered diol. [e] d.r. $>20: 1$ in all cases. [f] Run on $3.5 \mathrm{~g}$ of racemic diol with $0.5 \mathrm{~mol} \%$ of catalyst. [g] Monoester was also produced in $50 \%$ yield and $70.6: 29.4$ e.r.

allylic or benzylic positions (Table 1). Excellent results were obtained for both allylic diols (1a-d) and benzylic diols (1eh) series. Indeed, diols were recovered in $40-46 \%$ yield in enantiopure form in many cases, and correspond to excellent $s$ values between 15 and 73 . Similar results were obtained for the diesters with yields greater than $40 \%$ and e.r. values of greater than 97:3. Because of the symmetry of the substrates, it does not matter which hydroxy group undergoes the first acylation. It seems reasonable to propose that the two successive acylation reactions on one enantiomer of the anti-1,3-diol occur approximately at the same kinetic rate. The efficiency and the scalability of this new method were demonstrated by running the reaction with racemic $\mathbf{1 a}$ on a 3.5 gram scale. Optically active $(R, R)-\mathbf{1} \mathbf{a}(1.40 \mathrm{~g})$ and $(S, S)$ 2 a $(2.03 \mathrm{~g})$ were obtained with comparable excellent yields and selectivities using a reduced amount of catalyst ( $0.5 \mathrm{~mol} \%$; entry 1$)$. To discover the limits of the reaction, we examined the DoCKR of a diol without a $\pi$-system nearby the reactive centers (entry 9). Racemic yashabushidiol was tested under the standard reaction conditions, thus giving a monoester and the corresponding diester with poor enantioselectivity, but the recovered diol in $21 \%$ yield with a very high e.r. value (>99:1).

We expected that a significant step forward would be accomplished in terms of synthetic potential if this method- ology was applicable to unsymmetrical anti-1,3-diols. In such cases, the rates of the two successive acylation reactions might be significantly different, thus leading to a more complex kinetic sorting. Different series of substrates were prepared and evaluated in acylative DoCKR: diversely substituted anti-hepta-1,6-dien-3,5-diols (1i-k), anti-1,3-diarylpropan1,3-diols (11-n), and anti-1,5-diaryl-pent-1-en-3,5-diols (1os; Table 2). With these three series, $s$ values between 18 and 79 were obtained. High levels of enantioselectivity were reached with comparable yields for both the recovered diols and the diesters. The transformation tolerates heterocycles such as furan or thiophene derivatives (entries 5, 6, and 11), as well as trisubstituted double bonds (entries 2, 3, 9, and 10). Finally the DoCKR of the anti-1,3-diol 1t, presenting one benzylic alcohol and one secondary hydroxy group without a proximal $\pi$-system (e.g in either the allylic or benzylic position), was examined. The enantioselectivity of the recovered diol was not affected by this structural change and remained at a high level (99.5:0.5 e.r.), whereas the e.r. value of its diester was

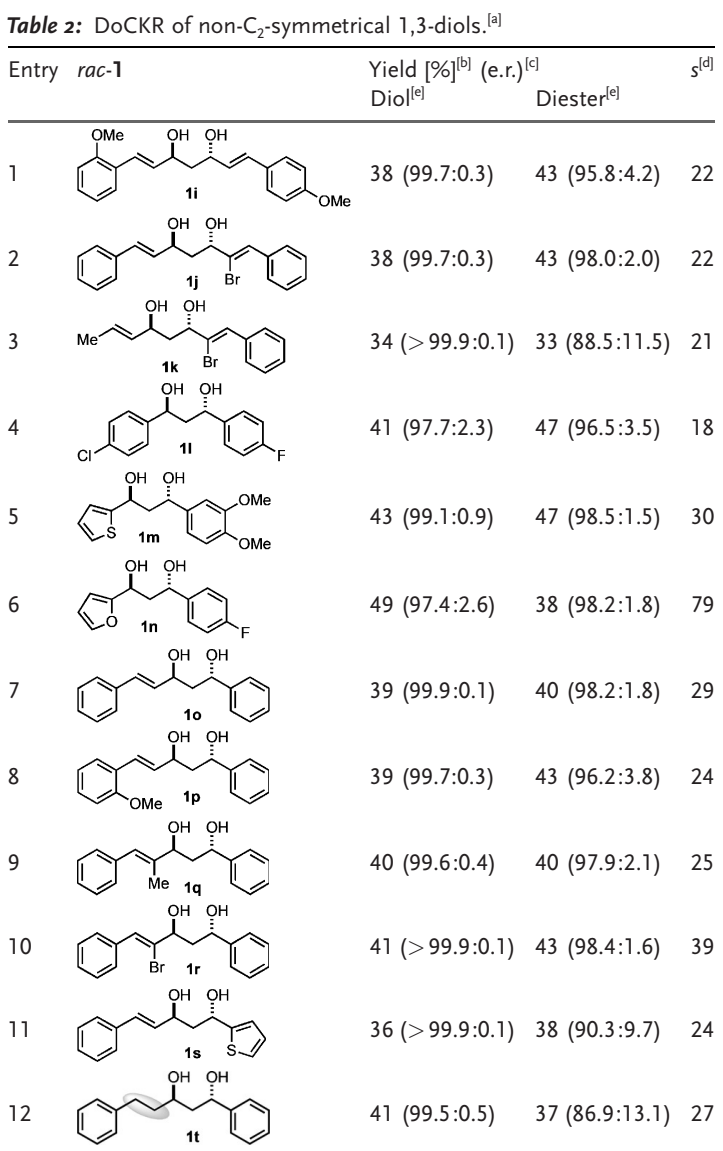

[a] Typical experiment performed on $0.5 \mathrm{mmol}$ of racemic diol under the standard reaction conditions. [b] Yield of isolated product. [c] Determined by HPLC analysis using a chiral stationary phase; for details see the Supporting Information. [d] Based on recovered diol. [e] d.r. $>20: 1$ in all cases. 
slightly lower. Its $s$ value ( 27 for $\mathbf{1 t}$ ) was quite similar to the unsaturated precursor $1 \mathbf{o}(s=29)$. This last example pinpoints the potential of the DoCKR process, to overcome a challenging selective transformation.

We decided to apply this methodology to the total synthesis of (+)-cryptocaryalactone ${ }^{[15]}$ a natural germination inhibitor (Scheme 5). The acylation reaction of the virtually

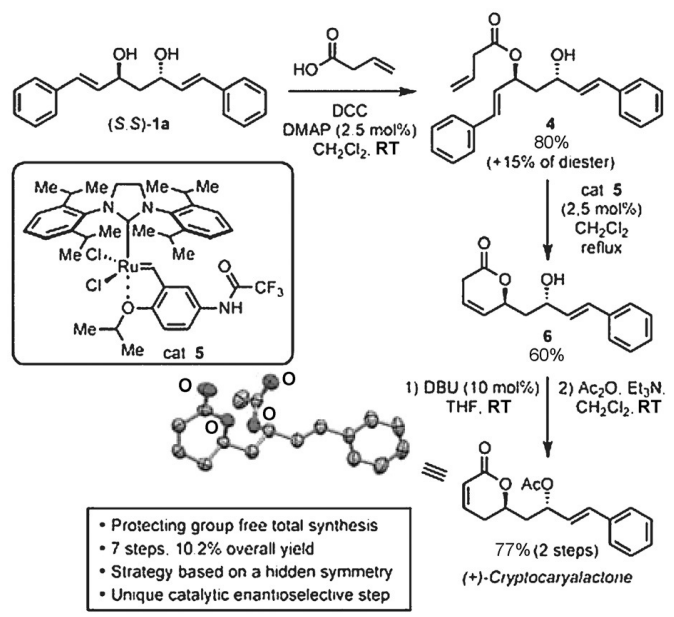

Scheme 5. Total synthesis of (+)-cryptocaryalactone. $\mathrm{DBU}=1,8$ diazabicyclo[5-4-0] undec-7-ene, DCC $=N, N$-dicyclohexylcarbodiimide, $\mathrm{DMAP}=4-(\mathrm{N}, \mathrm{N}$-dimethylamino $)$ pyridine, $\mathrm{THF}=$ tetrahydrofuran.

enantiopure $(S, S)$-1 a with vinylacetic acid under classical reaction conditions (DCC, DMAP cat., $\mathrm{CH}_{2} \mathrm{Cl}_{2}, \mathrm{RT}$ ) gave the monoester $4(80 \%)$ accompanied by a small amount of diester $(15 \%)$. The formed triene 4 then underwent a ringclosing metathesis reaction, using the highly active catalyst $5{ }^{[16]}$ to afford the lactone $\mathbf{6}$. Migration of the internal double bond under DBU catalysis ${ }^{[17]}$ and subsequent acylation reaction afforded $(+)$-cryptocaryalactone. ${ }^{[18]}$ This hiddensymmetry strategy ${ }^{[19]}$ represents the shortest synthesis of this target reported to date. ${ }^{[20]}$ Additionally, no protecting group was required for this synthesis, ${ }^{[21]}$ which involved a unique organocatalytic enantioselective step. ${ }^{[2]}$

In conclusion, we described a highly enantioselective synthetic separation of acyclic anti-1,3-diols, which are ubiquitous structural motifs in nature. This development was made possible by the design of a synergistic double catalytic kinetic resolution (DoCKR) and by a full exploitation of the additive Horeau principle. This efficient, general, and scalable method using an organocatalyzed acylation (0.5$1 \mathrm{~mol} \%$ catalyst loading) gives easy access to both enantiomers of a given acyclic anti-1,3-diol with high yields and enantioselectivities. The methodology was successfully applied to $\mathrm{C}_{2}$-symmetrical substrates and then further extended to the challenging and unprecedented cases of non- $\mathrm{C}_{2}$-symmetrical anti-1,3-diols. To the best of our knowledge, the use of such nonsymmetrical substrates bearing preexisting stereocenters in amplified systems has not yet been reported.
Finally, the effectiveness of the DoCKR was applied to an efficient total synthesis of (+)-cryptocaryalactone using a single catalytic enantioselective step. This flexible approach leads to both enantiomers, which are useful in total synthesis of natural product containing stereocenters with unassigned absolute configuration. All in all, we strongly believe that the concept of DoCKR could be of broader utility for the synthetic community and potentially transposed to other bifunctional substrates.

\section{Acknowledgements}

The authors warmly acknowledge Dr. X. Bugaut (AMU, iSm2) for proof reading, Dr. N. Vanthuyne, M. Jean (HPLC, iSm2), and Dr. M. Giorgi (RX, Spectropole, FR 1739). Aix Marseille Université (AMU), CNRS, COST ORCA Action 0905 (Organocatalysis), the French Research Ministry (Grant to J.M.) and Agence Nationale de la Recherche (Orcademe project ANR-10-JCJC-0710, Grant to P.B.) are also gratefully acknowledged for funding.

\section{Conflict of interest}

The authors declare no conflict of interest.

Keywords: diols · enantioselectivity - kinetic resolution · natural products organocatalysis

[1] J.-P. Vigneron, M. Dhaenes, A. Horeau, Tetrahedron 1973, 29 , 1055.

[2] V. Rautenstrauch, Bull. Soc. Chim. Fr. 1994, 131, 515

[3] For review, see: D. S. Glueck, Catal. Sci. Technol. 2011, 1, 1099.

[4] Selected examples: a) S. L. Schreiber, T. S. Schreiber, D. B. Smith, J. Am. Chem. Soc. 1987, 109, 1525; b) A. C. Spivey, S. J. Woodhead, M. Weston, B. I. Andrews, Angew. Chem. Int. Ed. 2001, 40, 769; Angew. Chem. 2001, 113, 791; c) K. Mori, Y. Ichikawa, M. Kobayashi, Y. Shibata, M. Yamanaka, T. Akiyama, J. Am. Chem. Soc. 2013, 135, 3964; d) R. J. Armstrong, M. D. Smith, Angew. Chem. Int. Ed. 2014, 53, 12822; Angew. Chem. 2014, 126, 13036; e) T. Osako, Y. Uozimi, Org. Lett. 2014, 16 , 5866 ; f) S. Tuong, A. Limouni, Q. Wang, M.-X. Wang, J. Zhu, Angew. Chem. Int. Ed. 2017, 56, 14192; Angew. Chem. 2017, 129 , 14380.

[5] Selected examples: a) B. S. Lucas, S. D. Burke, Org. Lett. 2003, 5, 3915; b) V. B. Birman, H. Jiang, X. Li, Org. Lett. 2007, 9, 3237; c) C. Roux, M. Candy, J.-M. Pons, O. Chuzel, C. Bressy, Angew. Chem. Int. Ed. 2014, 53, 766; Angew. Chem. 2014, 126, 785; d) J. Merad, P. Borkar, T. Bouyon Yenda, C. Roux, J.-M. Pons, J.-L. Parrain, O. Chuzel, C. Bressy, Org. Lett. 2015, 17, 2118; for a review in the context of total synthesis: e) J. Merad, M. Candy, J.-M. Pons, C. Bressy, Synthesis 2017, 49, 1938.

[6] Selected examples: Alkenes: a) G. A. Crispino, P. T. Ho, K. B. Sharpless, Science 1993, 259, 64; b) S. El Baba, K. Sartor, J.-C. Poulin, H. B. Kagan, Bull. Soc. Chim. Fr. 1994, 131, 525; c) Y. Huang, A. M. Walji, C. H. Larsen, D. W. C. MacMillan, J. Am. Chem. Soc. 2005, 127, 15051; d) J. Zhou, J. W. Ogle, Y. Fan, V. Banphavichit, Y. Zu, K. Burgess, Chem. Eur. J. 2007, 13, 7162; e) N. J. Green, A. L. Lawrence, G. Bojase, A. L. Willis, M. N. 
Paddon-Row, M. S. Sherburn, Angew. Chem. Int. Ed. 2013, 52 , 8333; Angew. Chem. 2013, 125, 8491; Ketones: f) M. Kitamura, T Ohkuma, S. Inoue, N. Sayo, H. Kumobayashi, S. Akutagawa, T. Ohta, H. Takaya, R. Noyori, J. Am. Chem. Soc. 1988, 110, 629; g) A. K. Dilger, V. Gopalasamuthiram, S. D. Burke, J. Am Chem. Soc. 2007, 129, 16273; h) Y. Lu, I. S. Kim, A. Hassan, D. J. Del Vall, M. J. Krische, Angew. Chem. Int. Ed. 2009, 48, 5018; Angew. Chem. 2009, 121, 5118; Enolates: i) J. A. Enquist, Jr., B. M. Stoltz, Nature 2008, 453, 1228.

[7] a) J. C. Ruble, J. Tweddell, G. Fu, J. Org. Chem. 1998, 63, 2794; b) P. Kumar, P. S. Chowdhury, M. Pandey, Adv. Synth. Catal. 2013, 355, 1719.

[8] For a review, see: a) D. Herkommer, B. Schmalzbauer, D. Menche, Nat. Prod. Rep. 2014, 31, 456; b) M. Kretschmer, D. Menche, Synlett 2010, 2989; c) K.-S. Yeung, I. Paterson, Chem. Rev. 2005, 105, 4237.

[9] For a review, see: S. E. Bode, M. Wolberg, M. Müller, Synthesis 2006, 557.

[10] For the two major reductive methods, see: a) D. A. Evans, K. T. Chapman, E. M. Carreira, J. Am. Chem. Soc. 1988, 110, 3560; b) D. A. Evans, A. H. Hoveyda, J. Am. Chem. Soc. 1990, 112, 6447.

[11] Aldol-Tischenko process : a) C. M. Mascarenhas, S. P. Miller, P. S. White, J. P. Morken, Angew. Chem. Int. Ed. 2001, 40, 601; Angew. Chem. 2001, 113, 621; b) V. Gnanadesikan, Y. Horiuchi, T. Ohshima, M. Shibasaki, J. Am. Chem. Soc. 2004, 126, 7782; Dynamic process: c) B. Martín-Matute, M. Edin, J.-E. Bäckvall, Chem. Eur. J. 2006, 12, 6053.

[12] For reviews on non-enzymatic catalytic KR, see: a) R. Gurubrahamam, Y.-S. Cheng, W.-Y. Huang, K. Chen, ChemCatChem 2016, 8, 86-96; b) H. Pellissier, Catalytic Kinetic Resolution, in Separation of Enantiomers: New Methods and Applications (Ed.: M. Todd), Wiley-VCH, Weinheim, 2014, Chap. 3, pp. 75-122; c) S. Arseniyadis, A. Spivey, Regio- and Position Selective Reactions and Desymmetrizations in Comprehensive Enantioselective Organocatalysis, Vol. 3 (Ed.: P. I. Dalko), Wiley-VCH, Weinheim, 2013, Chap. 41, pp. 1225-1284; d) C. Müller, P. R. Schreiner, Angew. Chem. Int Ed 2011, 50, 6012; Angew. Chem. 2011, 123, 6136; e) H. Pellissier, Adv. Synth. Catal. 2011, 353, 1613.

[13] a) C. Joannesse, C. P. Johnston, C. Concellon, C. Simal, D. Philp, A. D. Smith, Angew. Chem. Int. Ed. 2009, 48, 8914; Angew. Chem. 2009, 121, 9076; for reviews on chiral isothioureas as organocatalysts, see: b) J. Merad, J.-M. Pons, O. Chuzel, C. Bressy, Eur. J. Org. Chem. 2016, 5589 and also c) V. B. Birman, Aldrichimica Acta 2016, 49, 23.
14] H. B. Kagan, J.-C. Fiaud, Top. Stereochem. 1988, 18, 249

[15] Isolation: a) T. R. Govindachari, P. C. Parthasarathy, J. D. Modi, Ind. J. Chem. 1972, 10, 149; b) G. F. Spencer, R. E. England, R. B. Wolf, Phytochemistry 1984, 23, 2499-2500.

16] H. Clavier, F. Caijo, E. Borré, D. Rix, F. Boeda, S. P. Nolan, M. Mauduit, Eur. J. Org. Chem. 2009, 4254-4265. Unlike catalyst 5, classical metathesis catalysts lead to a mixture of products for this transformation.

[17] M.-A. Virolleaud, C. Bressy, O. Piva, Tetrahedron Lett. 2003, 44, $8081-8084$

[18] CCDC 1440921 contains the supplementary crystallographic data for this paper. These data can be obtained free of charge from The Cambridge Crystallographic Data Centre.

[19] For the total synthesis of natural products, involving an economic use of chiral reagents, from our group, see: a) $\mathrm{M}$. Candy, G. Audran, H. Bienaymé, C. Bressy, J.-M. Pons, J. Org. Chem. 2010, 75, 1354-1359; b) M. Candy, L. Tomas, S. Parat, V. Heran, H. Bienaymé, J.-M. Pons, C. Bressy, Chem. Eur. J. 2012, 18, 14267-14271 and ref. [5d].

[20] Previous syntheses: a) H. H. Meyer, Liebigs Ann. Chem. 1984, 977-981 (>9 steps); b) Y. Mori, H. Furukawa, Chem. Pharm. Bull. 1994, 42, 2161-2163 (>16 steps); c) G. Sabitha, V. Bhaskar, S. S. S. Reddy, J. S. Yadav, Tetrahedron 2008, 64, 10207-10213 (>13 steps); d) P. R. Krishna, K. Lopinti, K. L. N. Reddy, Beilstein J. Org. Chem. 2009, 5, 14 (>11 steps); e) G. Sabitha, B. Vangala, S. S. S. Reddy, J. S. Yadav, Helv. Chim. Acta 2010, 93, 329-338 (16 steps); f) P. Balasubramanyam, G. C. Reddy, N. Salvanna, B. Das, Synthesis 2011, $3706-$ 3710 (12 steps); g) J. S. Yadav, D. C. Bhunia, B. Ganganna, Tetrahedron Lett. 2012, 53, 2496-2499 (9 steps).

21] For reviews, see: a) R. N. Saicic, Tetrahedron 2014, 70, $8183-$ 8218; b) I. S. Young, P. S. Baran, Nat. Chem. 2009, 1, 193-205; c) R. W. Hoffmann, Synthesis 2006, 3531-3541.

22] For reviews about total syntheses involving an enantioselective organocatalysis, see: a) M. E. Abbasov, D. Romo, Nat. Prod. Rep. 2014, 31, 1318-1327; b) E. Marqués-López, R. P. Herrera, M. Christmann, Nat. Prod. Rep. 2010, 27, 1138-1167; c) R. M. de Figueiredo, M. Christmann, Eur. J. Org. Chem. 2007, $2575-$ 2600. 